\title{
The significance of triple oxygen isotope ratios of oceanic crust samples and cherts in understanding early Earth processes
}

\author{
DR. SUKANYA SENGUPTA ${ }^{1}$ AND ANDREAS PACK ${ }^{2}$ \\ ${ }^{1}$ Thermo Fisher Scientific \\ ${ }^{2}$ University of Göttingen \\ Presenting Author: sukanya.sengupta@thermofisher.com
}

The temperature and $\delta^{18} \mathrm{O}$ of earth's earliest oceans, where life may have originated, and their subsequent evolution over time is an important and long-debated question in Earth science. Constantly decreasing $\delta^{18} \mathrm{O}$ values of marine sediments over time have been explained by different possible scenarios - very hot seawater in the Archean [1], or much lower $\delta^{18} \mathrm{O}$ of seawater in the past [2], or diagenetic alteration [3]. A novel approach used in addressing this problem is the study of purely mass dependent triple oxygen isotope variations, i.e. combined $\delta^{17} \mathrm{O}$ and $\delta^{18} \mathrm{O}$, in oceanic crust samples and marine sediments like cherts.

High-precision $\delta^{18} \mathrm{O}$ and $\Delta^{, 17} \mathrm{O}$ values of low and high- $\mathrm{T}$ altered oceanic crust samples can be used to model the evolution of seawater oxygen isotope ratios over time in the triple oxygen isotope space [4]. This can be useful in interpreting the isotope variations seen in ancient marine sediments. The $\delta^{18} \mathrm{O}$ and the $\Delta{ }^{17} \mathrm{O}$ values of the chert samples from different locations and age groups, ranging from Archean to Phanerozoic, vary temporally from $\delta^{18} \mathrm{O}=15 \%$ and $\Delta{ }^{17} \mathrm{O}=-0.06 \%$ in Archean to $\delta^{18} \mathrm{O}=33 \%$ and $\Delta^{, 17} \mathrm{O}=-0.14 \%$ in Phanerozoic [5]. The data suggest neither a hot $80{ }^{\circ} \mathrm{C}$ Archean ocean, nor extremely low $\delta^{18} \mathrm{O} \sim-15 \%$ seawater values in the past. Rather, a hydrothermal formation or diagenetic alteration with no original ocean water temperature information preserved is a more likely explanation for the Precambrian chert samples.

The mass balance model for seawater evolution and the interpretations of the chert isotope data will be discussed with respect to the importance of high-precision triple oxygen isotope studies for fresh new insights into early earth processes.

[1] Knauth and Epstein, GCA, 1976,

[2] Perry, EPSL, 1967

[3] Degens and Epstein, AAPGB, 1962

[4] Sengupta and Pack, Chem. Geol., 2018

[5] Sengupta et al., Chem. Geol., 2020 